\title{
Fatores associados ao baixo risco cardiometabólico em mulheres obesas
}

\author{
Factors associated with low cardiometabolic risk in obese women
}

Maria Cecilia Costa', Luciara Leite Brito², Leila M. Batista Araújo ${ }^{3}$, Ines Lessa ${ }^{4}$

${ }^{1}$ Escola de Nutrição, Universidade Federal da Bahia (ENUFBA) Salvador, BA, Brasil

${ }^{2}$ Universidade Católica de Salvador (UCSal), Salvador, BA, Brasil ${ }^{3}$ Faculdade de Medicina,

Ambulatório de Obesidade, Hospita Universitário Professor Edgard Santos, Universidade Federal da Bahia (UFBA), Salvador, BA, Brasil ${ }^{4}$ Instituto de Saúde Coletiva (ISC), UFBA, Salvador, BA, Brasil
Correspondência para: Maria Cecilia Costa Rua General Antônio Sampaio, 203, ap. 301 - Pituba 41810-630 - Salvador, BA, Brasil marcosta@superig.com.br

Recebido em 3/Mai/2009 Aceito em 16/Out/2009

\begin{abstract}
RESUMO
Objetivo: Identificar fatores associados ao baixo risco cardiometabólico (RCM) em mulheres obesas $\left(\mathrm{MO}_{\mathrm{b}}\right)$ atendidas em ambulatórios especializados do Sistema Único de Saúde (SUS), Salvador, Bahia, Brasil. Sujeitos e métodos: Estudo caso-controle, pareado pela idade com 306 $\mathrm{MO}_{\mathrm{b}^{\prime}}$ índice de massa corporal $(\mathrm{IMC}) \geq 30 \mathrm{~kg} / \mathrm{m}^{2}$, sendo $66(21,6 \%)$ casos - todos não hipertensos, normolipídicos e não diabéticos e 240 (78,4\%) controles. Dados secundários foram obtidos dos prontuários médicos e primários por meio de inquérito domiciliar e exames laboratoriais. Foram realizadas análises descritiva, bivariada e regressão logística condicional. Resultados: Associações positivas, estatisticamente significantes, foram detectadas entre baixo RCM e consumo de frutas ( $\geq 3$ porções/dia) $\left(\mathrm{OR}_{\mathrm{aj}}=20,1 ; \mathrm{IC} 95 \%: 5,6-71,9\right) ; \mathrm{PCR}$ do $1^{\circ}$. quartil $\left(\mathrm{OR}_{\mathrm{aj}}=4,1 ; \mathrm{IC} 95 \%: 2,0-8,3\right)$ e da adiponectina plasmática (AdipoO) a partir do $3^{\circ}$. quartil $\left(\mathrm{OR}_{\mathrm{aj}}=2,3 ; \mathrm{IC} 95 \%: 1,1-4,8\right)$. Conclusão: Este estudo sugere que dieta rica em fibras solúveis ( $\geq 3$ porções de frutas/dia), valores da $\mathrm{PCR} \leq 3,70 \mathrm{mg} / \mathrm{L}$ e da Adipo $\mathrm{Q}>10,00 \mu \mathrm{g} / \mathrm{mL}$ podem dificultar, retardar ou impedir o aparecimento de outros fatores de risco ou doenças metabólicas em $\mathrm{MO}_{\mathrm{b}}$. Arq Bras Endocrinol Metab. 2010;54(1):68-77

Descritores

Fatores metabolicoprotetores; risco cardiometabólico; mulheres obesas
\end{abstract}

\begin{abstract}
Objective: To identify factors associated with low cardiometabolic risk (CMR) in obese women $\left(\mathrm{O}_{\mathrm{b}} \mathrm{W}\right)$ seen at outpatient specialty clinics of SUS (Brazilian Social Security Health System), in the City of Salvador, Bahia, Brazil. Subjects and methods: Case-control study, matched by age, of $306 \mathrm{O}_{\mathrm{b}} \mathrm{W}$ (BMI $\left.\geq 30 \mathrm{~kg} / \mathrm{m}^{2}\right)$, including $66(21.6 \%)$ cases - normotensive, normolipidemic and nondiabetic patients - and $240(78.4 \%)$ controls. Secondary data were obtained from clinical records, and primary data were collected by means of a household survey and laboratory assays. Descriptive, bivariate, and conditional logistic regression analyses were conducted. Results: A positive, statistically significant association was found between low CMR and a diet containing the desirable ingestion of fruit (AOR $=20.1, \mathrm{Cl} 95 \%$ 5.6-71.9); $1^{\text {st }} \mathrm{CRP}$ quartile ( $\left.\mathrm{AOR}=4.1, \mathrm{Cl} 95 \% 2.0-8.3\right)$, and $3^{\text {rd }}$ and $4^{\text {th }}$ AdipoO quartiles ( $A O R=2.3, \mathrm{Cl} 95 \%$ 1.1-4.8). Conclusion: This study suggests that a diet rich in soluble fibers as well as lower levels of CRP, and higher levels of AdipoQ, encumber, retard or impede the emergence of other metabolic risk factors or metabolic diseases in $\mathrm{O}_{\mathrm{b}} \mathrm{W}$. Arq Bras Endocrinol Metab. 2010;54(1):68-77
\end{abstract}

Keywords

Protective factors; cardiometabolic risk; obese women

\section{INTRODUÇÃO}

Aíndrome metabólica (SM) apresenta-se atualmenAte como pandemia, predominando em mulheres. Caracteriza-se pela combinação de pelo menos três entre os cinco fatores metabólicos de risco cardiovascular (obesidade central, valores considerados indesejáveis da glicemia, dos triglicérides, do HDL-colesterol e da pressão arterial - PA), sendo a obesidade central o mais presente e o mais potente determinante entre os demais $(1,2)$. Essa combinação é intermediada ou impulsionada por marcadores de inflamação, entre eles, a proteína $C$ reativa (PCR) sérica elevada (3). Alguns autores propõem a sua inclusão entre os componentes da SM, não só pela sua forte associação com os 
componentes dessa síndrome, como também pelo seu importante papel no desenvolvimento e na progressão da aterosclerose e, consequentemente, do risco cardiovascular $(1,3,4)$.

Mais recentemente, a adiponectina plasmática (AdipoQ) foi identificada como um outro marcador inflamatório produzido no tecido adiposo, sugerindo que sua ação seja antiaterogênica e anti-inflamatória, aumentando a sensibilidade à insulina, com tendência aos valores mais baixos em indivíduos obesos quando comparados aos não obesos. Seus níveis elevados parecem proteger contra doenças metabólicas $(5,6)$. Geralmente variam de 3 a $30 \mu \mathrm{g} / \mathrm{mL}$, sendo consideravelmente mais altos do que os de outras substâncias que atuam tanto sobre o tecido adiposo quanto na participação da regulação de diversos processos metabólicos (6).

A partir das últimas décadas, observam-se evidências de que, apesar de os obesos apresentarem grande quantidade de massa gorda, existe um subgrupo com níveis relativamente altos de sensibilidade à insulina $\mathrm{e}$ um perfil metabólico favorável ao não desenvolvimento de outros riscos cardiometabólicos (RCM) $(7,8)$. Teoricamente, tais obesos parecem "protegidos" do desenvolvimento de outras perturbações metabólicas que, com a obesidade, configuram RCM. Presume-se, portanto, que indivíduos com esse perfil diferenciam-se dos demais obesos pela presença de algum fator "protetor" que lhes confere baixo risco de RCM, em oposição aos obesos com múltiplos FRCM.

Os fatores de proteção podem ser atribuídos a elementos positivos herdados ou adquiridos durante $o$ curso da vida, que contribuem para o indivíduo superar o risco (9), contudo, fatores de proteção e fatores de risco dependem da relação estabelecida entre as características individuais e o contexto socioambiental.

A identificação de fatores de "proteção" em obesos sem outros RCM poderá contribuir para a implementação de medidas intervencionistas desfavoráveis à aquisição de FRCM pela população, independentemente da presença de obesidade. Assim, com este estudo pretendeu-se identificar fatores associados ao baixo risco cardiometabólico em mulheres obesas.

\section{SUJEITOS E MÉTODOS}

O desenho do estudo é do tipo caso-controle pareado pela idade. Para sua execução, foram selecionados, por conveniência, os dois únicos ambulatórios do Sistema Único de Saúde (SUS), referência para tratamento da obesidade no Estado da Bahia, localizados no Município de Salvador: o Magalhães Neto, no Hospital Universitário Professor Edgard Santos da Universidade Federal da Bahia (UFBA), e o Centro de Referência Estadual para Assistência ao Diabetes e Endocrinologia (Cedeba), da Secretaria da Saúde do Estado da Bahia (Sesab). Nas duas instituições, todos os pacientes admitidos apresentavam índice de massa corporal (IMC) $\geq 30 \mathrm{~kg} / \mathrm{m}^{2}$ na presença ou não de comorbidades associadas.

Em 2006, 465 indivíduos obesos, 43 (9,2\%) homens e $422(90,8 \%)$ mulheres, na faixa etária de 20 a 75 anos, estavam matriculados nos ambulatórios. Foram critérios de inclusão no estudo: sexo feminino; idade entre 20 e 59 anos; residência fixa em Salvador; estar sendo acompanhada em apenas um dos ambulatórios; não ter sido submetida à cirurgia bariátrica; ter registro de pelo menos uma consulta ambulatorial no período com exames laboratoriais, e não ter sido tratada para obesidade, hipertensão arterial sistêmica (HAS), diabetes melito (DM) e dislipidemias. Das 422 mulheres, $116(27,5 \%)$ não atenderam aos critérios de inclusão. Participaram do estudo 306 mulheres, sendo $66(21,6 \%)$ casos e $240(78,4 \%)$ controles. O projeto foi aprovado pelo Comitê de Ética da Maternidade Climério de Oliveira - UFBA (Parecer/Resolução n ${ }^{\circ}$. $110 / 2005)$. Após a aprovação, o Parecer foi discutido pelo Comitê de Ética do Cedeba, que o ratificou, disponibilizando a consulta aos prontuários das pacientes do ambulatório de obesidade. Todas as participantes foram informadas sobre o estudo e assinaram o termo de consentimento.

Foram definidas como casos mulheres obesas sem outros FRCM, ou seja, que apresentassem: a) colesterol total $<200 \mathrm{mg} / \mathrm{dL} ;$ LDL-colesterol $<130$ $\mathrm{mg} / \mathrm{dL}$; HDL-colesterol $\geq 50 \mathrm{mg} / \mathrm{dL}$; triglicérides < $150 \mathrm{mg} / \mathrm{dL}$; b) pressão arterial $(\mathrm{PA})<130 / 85 \mathrm{mmHg}$ e não ser hipertensa; c) glicemia de jejum $<100 \mathrm{mg} /$ $\mathrm{dL}$ e não ser diabética. Os controles foram as mulheres obesas que apresentavam valores indesejáveis para as variáveis acima mencionadas, combinados ou não. Para cada caso, foram selecionados três a quatro controles com diferença de idade de até \pm 5 anos. A coleta de dados ocorreu em três etapas a seguir descritas.

A etapa I consistiu na coleta de dados secundários dos prontuários médicos, de acordo com os critérios de inclusão estabelecidos para o estudo: a) sociodemográficos - idade, cor da pele, estado civil, grau de escolaridade e nível socioeconômico; b) clínico-epidemiológicos - início precoce/tardio da obesidade; estilo de vida 
e fatores psicocomportamentais (dieta habitual, atividade física, consumo de bebida alcoólica, tabagismo, transtornos alimentares, hiperfagia noturna); c) clínicos - dislipidemias, DM, HAS; uso de medicamentos para dislipidemias, DM e HAS; uso de outros medicamentos para: depressão, reposição do hormônio tireoidiano, contraceptivo oral ou reposição hormonal a partir da menopausa; d) dados dos pais - obesidade, HAS e DM; e) dados complementares - antropométricos (peso, altura e perímetro da cintura) e laboratoriais (colesterol e frações, triglicérides e glicemia em jejum). Os dados selecionados foram transcritos por estudantes de medicina para uma ficha padronizada. Foi realizada análise de consistência em $20 \%$ dos prontuários.

A etapa II correspondeu ao pré-teste do questionário e à entrevista domiciliar. $\mathrm{O}$ pré-teste visou testar a funcionalidade do instrumento. Foi aplicado em 36 mulheres obesas em um ambulatório de nutrição de um Centro de Estudos de Saúde da Secretaria de Saúde do Estado da Bahia, pela similaridade das suas características com os serviços estudados.

Os entrevistadores tinham nível secundário completo e experiência em trabalho de campo. Todos foram treinados durante uma semana e avaliados quanto ao domínio das questões e à habilidade no questionamento. Após a capacitação, os entrevistadores executaram o pré-teste em 60 mulheres obesas. Uma amostra de $20 \%$ dos questionários foi reaplicada por telefone, com questões escolhidas aleatoriamente, visando ao controle de qualidade.

Os dados primários sobre fatores socioambientais, psicocomportamentais e biológicos foram obtidos por inquérito domiciliar, contendo perguntas sobre dados pessoais, antecedentes médicos e uso de medicamentos referentes ao primeiro atendimento ambulatorial, para confronto entre alguns dados primários e secundários. No segundo bloco, foram formuladas perguntas que permitissem o detalhamento das práticas alimentares, transtornos alimentares e atividade física, referenciados no primeiro atendimento ambulatorial. Buscou-se também investigar o comportamento alimentar e a atividade física anterior e atual, a fim de facilitar o resgate da informação dependente da memória da participante.

$\mathrm{Na}$ etapa III, as mulheres realizaram dosagem da PCR ultrassensível (PCR), da adiponectina plasmática (AdipoQ), do perfil lipídico e da glicemia em jejum. Nenhuma das participantes usou drogas hipolipemiantes enquanto acompanhadas em ambulatório. A coleta de sangue foi realizada pós-jejum de 12 horas (4). Nes- ta etapa, as participantes responderam a um miniquestionário para confirmação dos critérios de definição dos casos e controles e atualização das informações quanto ao uso e aos tipos de medicamentos no período entre o início do acompanhamento ambulatorial e o momento atual, além da confirmação do diagnóstico de HAS, DM e dislipidemias. Foram também realizadas medidas do peso, altura, perímetro abdominal e da pressão arterial. Os resultados dos exames foram encaminhados para a chefia de cada um dos ambulatórios.

A PCR foi medida pelo método nefelométrico, com limite de detecção de $0,15 \mathrm{mg} / \mathrm{L}$, a AdipoQ, pelo método ELISA Adiponectina Humana, com limite de detecção de $0,5 \mu \mathrm{g} / \mathrm{mL}$; a determinação do perfil lipídico e da glicemia em jejum, por método enzimático e equipamento bioanalisador totalmente automatizado. Para a determinação dos pontos de corte da PCR e da AdipoQ, foram estimados quartis.

Os dados coletados passaram por controle de qualidade, sendo armazenados no programa Excel, versão 2003, para sistema Windows. Para esse estudo, considerou-se apenas o consumo das quantidades de frutas registradas no prontuário médico, por serem geralmente consumidas in natura e sua maioria conter baixo índice e carga glicêmicos (10), sendo ricas em fibras solúveis que ajudam na eliminação do colesterol (4).

As variáveis foram categorizadas (Tabela 1) e as análises realizadas no programa Stata, versão 9.1, para sistema Windows.

Para as características da população investigada, foram realizadas análises descritivas (univariadas). Para estimar a associação entre o baixo risco cardiometabólico e as demais variáveis, inicialmente foram realizadas análises bivariadas para testar significância das associações (teste Qui-quadrado de Pearson). Posteriormente, foram efetuadas análises multivariadas pela regressão logística condicional tipo forward, a partir de um modelo teórico definido a priori, discriminando-se os fatores de "proteção" em blocos hierarquizados e respeitando-se a hierarquia existente entre os níveis de determinação de risco cardiometabólico. A estratégia utilizada para a entrada dos blocos $(\mathrm{n}=4)$ de variáveis foi por intermédio do módulo em passos, conforme a figura 1. Foram mantidas no modelo as variáveis com níveis de significância estatística (valor de $\mathrm{p} \leq 0,15)$ para ajuste das demais variáveis do modelo. Considerou-se estatisticamente significante (ES) quando, na associação entre as variáveis, observou-se valor de $\mathrm{p} \leq 0,05$. 
Tabela 1. Categorização das variáveis selecionadas para o estudo

\begin{tabular}{|c|c|}
\hline Variáveis & Categorização \\
\hline \multicolumn{2}{|l|}{ Dependente } \\
\hline \multirow{2}{*}{$\begin{array}{l}\text { Risco } \\
\text { cardiometabólico } \\
\text { (RCM) }\end{array}$} & $\begin{array}{l}\text { Baixo - presença de obesidade na ausência de outros } \\
\text { FRCM }\end{array}$ \\
\hline & $\begin{array}{l}\text { Médio ou alto - presença de obesidade associada a } \\
\text { outros FRCM, combinados ou não }\end{array}$ \\
\hline \multicolumn{2}{|l|}{ Independentes } \\
\hline \multirow[t]{2}{*}{ Cor da pele } & Branca \\
\hline & Parda ou preta \\
\hline \multirow[t]{2}{*}{ Grau de escolaridade } & Médio - ter, no mínimo, o ensino fundamental I completo \\
\hline & $\begin{array}{l}\text { Baixo - ser analfabeta ou ter o ensino fundamental I } \\
\text { incompleto }\end{array}$ \\
\hline \multirow{2}{*}{$\begin{array}{l}\text { Nível socioeconômico } \\
\text { (IBGE) }\end{array}$} & Médio - estrato "C" \\
\hline & Baixo - estrato "D" \\
\hline \multirow[t]{2}{*}{ Estado civil } & Solteira \\
\hline & $\begin{array}{l}\text { Casada ou não mais casada (casada, convive } \\
\text { maritalmente ou viúva) }\end{array}$ \\
\hline \multirow{2}{*}{$\begin{array}{l}\text { Obesidade (0b) de } \\
\text { início }\end{array}$} & Tardio - desenvolvida na fase adulta \\
\hline & Precoce - desenvolvida na infância ou na adolescência \\
\hline \multirow{2}{*}{$\begin{array}{l}\text { Histórico de Ob, DM e } \\
\text { HAS dos pais }\end{array}$} & Não - nenhum dos pais tem ou tinha \\
\hline & Sim - pelo menos um dos pais tem ou tinha \\
\hline \multirow{2}{*}{$\begin{array}{l}\text { Consumo de bebida } \\
\text { alcoólica }\end{array}$} & Não - nunca consumiu bebida alcoólica \\
\hline & Sim - tem o hábito de consumir bebida alcoólica \\
\hline \multirow[t]{2}{*}{ Tabagismo } & Não - nunca fumou \\
\hline & Sim - fumante ou ex-fumante \\
\hline \multirow[t]{2}{*}{$\begin{array}{l}\text { Uso de outros } \\
\text { medicamentos }\end{array}$} & $\begin{array}{l}\text { Não - não faz uso de medicamentos: depressão, } \\
\text { hormônio tireoidiano, contraceptivo oral ou reposição } \\
\text { hormonal a partir da menopausa }\end{array}$ \\
\hline & $\begin{array}{l}\text { Sim - faz uso de medicamentos: depressão, hormônio } \\
\text { tireoidiano, contraceptivo oral ou reposição hormonal a } \\
\text { partir da menopausa }\end{array}$ \\
\hline \multirow[t]{2}{*}{ AdipoQ } & $>10,00 \mu \mathrm{gg} / \mathrm{mL}$ (a partir do $3^{0}$ quartil) \\
\hline & $\leq 10,00 \mu \mathrm{g} / \mathrm{mL}$ (incluídos no $1^{\circ}$ e no $2^{\circ}$ quartis) \\
\hline \multirow[t]{2}{*}{ PCR } & $\leq 3,70$ mg/L (incluídos no $1^{\circ}$ quartil) \\
\hline & > 3,70 mg/L (a partir do $2^{0}$ quartil) \\
\hline \multirow[t]{2}{*}{ Atividade física } & $\begin{array}{l}\text { Ativa - desenvolve diariamente atividades domésticas, } \\
\text { de lazer com exercícios aeróbicos e remuneradas que } \\
\text { demandem movimentação constante }\end{array}$ \\
\hline & $\begin{array}{l}\text { Pouco ativa - desenvolve eventualmente atividades } \\
\text { domésticas, de lazer com exercícios aeróbicos e } \\
\text { remuneradas que demandem movimentação constante }\end{array}$ \\
\hline \multirow[t]{2}{*}{ Consumo de frutas } & $\begin{array}{l}\text { Desejável - três ou mais porções/dia de } \\
\text { aproximadamente }(\approx) 100 \mathrm{~g}\end{array}$ \\
\hline & $\begin{array}{l}\text { Indesejável - não consome ou consome até duas } \\
\text { porções/dia de } \approx 100 \mathrm{~g}\end{array}$ \\
\hline \multirow[t]{2}{*}{ Compulsão alimentar } & $\begin{array}{l}\text { Ausência - ingerir regularmente quantidades de } \\
\text { alimentos dissociadas da perda de controle sobre } 0 \\
\text { episódio de consumo alimentar }\end{array}$ \\
\hline & $\begin{array}{l}\text { Presença - ingerir diferentes quantidades de alimentos } \\
\text { associadas à perda de controle sobre o episódio de } \\
\text { consumo alimentar }\end{array}$ \\
\hline \multirow[t]{2}{*}{ Hiperfagia noturna } & $\begin{array}{l}\text { Ausência - não interromper o sono para consumir } \\
\text { alimentos }\end{array}$ \\
\hline & Presença - interromper o sono para consumir alimentos \\
\hline
\end{tabular}

BLOCO 1. Histórico de doenças crônicas não transmissíveis Obesidade, DM, HAS entre os pais e início de obesidade das participantes do estudo

BLOCO 2. Fatores demográficos e socioeconômicos Cor da pele; estado civil; grau de escolaridade e nível socioeconômico

BLOCO 3. Estilo de vida e fatores psicocomportamentais Consumo de frutas; atividade física; bebida alcoólica; tabagismo; compulsão alimentar e hiperfagia noturna

BLOCO 4. Marcadores inflamatórios e uso de medicamentos Níveis de PCR e de adiponectina plasmática; uso de medicamentos para: depressão, hormônio tireoidiano, contraceptivo oral e reposição hormonal a partir da menopausa

Baixo risco cardiometabólico

Colesterol total $<200 \mathrm{mg} / \mathrm{dL}$; LDL-colesterol $<130 \mathrm{mg} / \mathrm{dL}$; $\mathrm{HDL}$-colesterol $\geq 50 \mathrm{mg} / \mathrm{dL}$; triglicérides $<150 \mathrm{mg} / \mathrm{dL}$;

$\mathrm{PA}<130 / 85 \mathrm{mmHg}$ e não ser hipertensa; glicemia de jejum $<100 \mathrm{mg} / \mathrm{dL}$ e não ser diabética

Figura 1. Modelo hierárquico do processo de determinação dos fatores de "proteção" para baixo risco cardiometabólico em mulheres adultas obesas.

\section{RESULTADOS}

Os valores médios da idade, IMC e perímetro abdominal foram semelhantes entre casos e controles, na triagem e na confirmação dos critérios de definição dos referidos grupos. Também se verificou que níveis médios da PCR foram mais baixos entre os casos quando comparados aos controles, o inverso ocorrendo com a AdipoQ (Tabela 2).

Diferenças ES entre casos e controles foram constatadas em relação ao: início da obesidade, consumo de $\geq$ três porções frutas/dia, e não uso de medicamento para depressão, não uso de contraceptivo oral, e valores da PCR, e da AdipoQ (Tabela 3).

A partir da primeira etapa da análise de regressão logística condicional, foi constatado que o baixo RCM esteve associado positivamente às mulheres cujos pais não eram diabéticos, não eram hipertensos e não eram obesos, sendo essas associações não estatisticamente significantes (NES). Por outro lado, a ocorrência de obesidade iniciada na fase adulta apresentou associação negativa e ES.

$\mathrm{Na}$ segunda etapa da análise, as variáveis demográficas e socioeconômicas foram ajustadas pela variável início da obesidade, observando-se associação positiva, mas NES entre baixo RCM e estado civil solteira e pertencer à classe média. Com relação ao grau de escolaridade, verificou-se que a associação positiva, identificada 
na análise bruta, mostrou-se negativa, e NES após ajuste por variáveis potencialmente confundidoras.

Seguindo o modelo teórico, as variáveis estilo de vida e fatores psicocomportamentais foram ajustadas pelas variáveis início da obesidade e nível socioeconômico, observando-se que o baixo RCM esteve associado positivamente, mas NES ao não consumo de bebidas alcoólicas e nunca ter fumado. Ressalta-se que as mulheres obesas que referiram consumo de $\geq$ três porções de fruta/dia apresentam chance muito elevada de ter baixo RCM, sendo essa associação ES. Constatou-se, ainda, que a associação foi negativa entre RCM e ausência de compulsão alimentar, de hiperfagia noturna e ser ativa, entretanto, essas associações não foram ES.

Entre as variáveis do último bloco, verificou-se associação positiva ES entre ter baixo RCM e níveis de PCR $\leq 3,70 \mathrm{mg} / \mathrm{L}$ e de AdipoQ > 10,00 $\mu \mathrm{g} / \mathrm{mL}$. Associaram-se positivamente ao baixo RCM, porém NES, não fazer reposição do hormônio tireoidiano e não fazer uso de contraceptivo oral, e negativamente ao baixo RCM, não fazer reposição hormonal a partir da menopausa, sendo também NES. Constatou-se, ainda, que a associação entre o não uso de antidepressivo e o baixo RCM foi negativa e ES (Tabela 4).

Os dados apresentados na tabela 5 mostram que as variáveis, do estilo de vida e fatores psicomportamen- tais, contribuíram significativamente para a explicação do baixo RCM. Constatou-se, ainda, elevação no percentual de explicação quando foram incluídos na modelagem os marcadores inflamatórios e uso de medicamentos (Tabela 5)

\section{DISCUSSÃO}

Alguns aspectos metodológicos do estudo merecem discussão, dado que podem sugerir a ocorrência de bias de seleção e de aferição: 1) a população do estudo corresponde ao universo de mulheres obesas que preencheram os critérios de inclusão. Excluídos os casos, todas as demais mulheres apresentavam dois ou mais FRCM; 2) com os cuidados metodológicos adotados pode-se inferir a validade interna do estudo; 3 ) os casos e os controles podem não representar suas populações de origem, portanto, a extrapolação só poderá ser feita para grupos com características similares às deste estudo e 4) a ocorrência de bias de seleção (viés de Berkson) e a possibilidade de detectar-se ou não fatores de "proteção" nos casos teoricamente não influenciaram a busca do atendimento ambulatorial pelas mulheres obesas, pois os ambulatórios são destinados ao tratamento da obesidade, independentemente da presença de qualquer outra comorbidade.

Tabela 2. Média, desvio-padrão (DP) das variáveis que caracterizam os casos e os controles

\begin{tabular}{|c|c|c|c|c|c|c|}
\hline \multirow[b]{2}{*}{ Variáveis } & \multicolumn{2}{|c|}{ Etapa la } & \multirow[b]{2}{*}{ Valor de $\mathbf{p}$} & \multicolumn{2}{|c|}{ Etapa II } & \multirow[b]{2}{*}{ Valor de $p$} \\
\hline & $\begin{array}{c}\text { Caso } \\
n=66 \\
\text { Média (DP) }\end{array}$ & $\begin{array}{c}\text { Controle } \\
n=240 \\
\text { Média (DP) }\end{array}$ & & $\begin{array}{c}\text { Caso } \\
n=66 \\
\text { Média (DP) }\end{array}$ & $\begin{array}{c}\text { Controle } \\
n=240 \\
\text { Média (DP) }\end{array}$ & \\
\hline Idade (anos) & $39,0(8,7)$ & $41,0(8,2)$ & 0,09 & $41,5(8,8)$ & $43,3(8,4)$ & 0,13 \\
\hline IMC (kg/m²) & $43,0(6,5)$ & $43,1(6,4)$ & 0,95 & $42,6(8,0)$ & $42,9(7,1)$ & 0,73 \\
\hline Perímetro abdominal (cm) & $125,0(13,7)$ & $124,6(15,4)$ & 0,85 & $125,0(13,9)$ & $124,7(15,4)$ & 0,86 \\
\hline PCR (mg/L) & * & * & & $3,9(1,9)^{\star \star}$ & $10,2(6,4)^{\star \star}$ & 0,00 \\
\hline AdipoQ $(\mu \mathrm{g} / \mathrm{mL})$ & $\#$ & \# & & $14,8(6,5)^{\# \#}$ & $10,1(2,6)^{\# \#}$ & 0,00 \\
\hline \multicolumn{7}{|c|}{ Critérios de definição dos grupos } \\
\hline Colesterol total (mg/dL) & $169,9(20,7)$ & $238,0(48,9)$ & 0,00 & $174,9(18,6)$ & $241,3(49,7)$ & 0,00 \\
\hline HDL-colesterol (mg/dL) & $58,3(8,9)$ & $40,9(10,1)$ & 0,00 & $57,1(6,9)$ & $38,9(7,4)$ & 0,00 \\
\hline LDL-colesterol (mg/dL) & $92,2(22,5)$ & $159,2(48,7)$ & 0,00 & $99,9(20,3)$ & $186,9(46,6)$ & 0,00 \\
\hline Triglicérides (mg/dL) & $96,6(19,7)$ & $189,0(51,5)$ & 0,00 & $94,4(18,2)$ & $203,7(39,6)$ & 0,00 \\
\hline Glicemia em jejum (mg/dL) & $86,2(6,7)$ & $102,4(26,0)$ & 0,00 & $86,7(6,4)$ & $116,1(26,6)$ & 0,00 \\
\hline PAS (mmHg) & $116,9(8,3)$ & $137,8(18,1)$ & 0,00 & $117,0(7,6)$ & $141,3(12,8)$ & 0,00 \\
\hline PAD (mmHg) & $73,5(6,8)$ & $87,7(12,0)$ & 0,00 & $73,5(6,4)$ & $88,7(8,9)$ & 0,00 \\
\hline
\end{tabular}


Tabela 3. Perfil epidemiológico dos casos e dos controles, na etapa I

\begin{tabular}{|c|c|c|c|c|c|}
\hline \multirow[t]{2}{*}{ Perfil epidemiológico } & \multicolumn{2}{|c|}{$\begin{array}{l}\text { Casos } \\
n=66\end{array}$} & \multicolumn{2}{|c|}{$\begin{array}{c}\text { Controles } \\
n=240\end{array}$} & \multirow{2}{*}{$\begin{array}{l}\text { Valor } \\
\text { de p }\end{array}$} \\
\hline & $\mathbf{n}$ & $\%$ & $\mathbf{n}$ & $\%$ & \\
\hline \multicolumn{6}{|l|}{ Morbidade dos pais } \\
\hline \multicolumn{6}{|l|}{ Diabetes melito ${ }^{\mathrm{a}}$} \\
\hline Nenhum & 36 & 54,6 & 116 & 48,3 & \\
\hline Pelo menos um & 30 & 45,4 & 124 & 51,7 & 0,37 \\
\hline \multicolumn{6}{|c|}{ Hipertensão arterial sistêmica } \\
\hline Nenhum & 16 & 24,2 & 53 & 22,1 & \\
\hline Pelo menos um & 50 & 75,8 & 187 & 77,9 & 0,71 \\
\hline \multicolumn{6}{|l|}{ Obesidade ${ }^{\mathrm{a}}$} \\
\hline Nenhum & 40 & 60,6 & 159 & 66,2 & \\
\hline Pelo menos um & 26 & 39,4 & 81 & 33,8 & 0,39 \\
\hline \multicolumn{6}{|l|}{ Biológicas } \\
\hline \multicolumn{6}{|l|}{ Cor da pele ${ }^{\mathrm{a}}$} \\
\hline Branca & 20 & 30,3 & 76 & 31,7 & \\
\hline Parda ou preta & 46 & 69,7 & 164 & 68,3 & 0,83 \\
\hline \multicolumn{6}{|l|}{$\mathrm{PCR}^{\mathrm{b}}$} \\
\hline$\leq 3,70 \mathrm{mg} / \mathrm{L}$ & 35 & 53,0 & 43 & 17,9 & \\
\hline$>3,70 \mathrm{mg} / \mathrm{L}$ & 31 & 47,0 & 197 & 82,1 & 0,00 \\
\hline \multicolumn{6}{|l|}{ AdipoQb } \\
\hline$>10,00 \mu \mathrm{g} / \mathrm{mL}$ & 41 & 62,1 & 104 & 43,3 & \\
\hline$\leq 10,00 \mu \mathrm{g} / \mathrm{mL}$ & 25 & 37,9 & 136 & 56,7 & 0,01 \\
\hline \multicolumn{6}{|l|}{ História pessoal } \\
\hline \multicolumn{6}{|l|}{ Início da obesidade ${ }^{\mathrm{a}}$} \\
\hline Tardia & 27 & 40,9 & 137 & 57,1 & \\
\hline Precoce & 39 & 59,1 & 103 & 42,9 & 0,02 \\
\hline \multicolumn{6}{|l|}{ Contraceptivo oral ${ }^{\mathrm{a}}$} \\
\hline Não usa & 56 & 84,9 & 175 & 72,9 & \\
\hline Usa & 10 & 15,1 & 65 & 27,1 & 0,05 \\
\hline \multicolumn{6}{|c|}{ Reposição hormonal a partir da } \\
\hline \multicolumn{6}{|l|}{ menopausa ${ }^{a}$} \\
\hline Não faz & 60 & 90,9 & 219 & 91,2 & \\
\hline Faz & 6 & 9,1 & 21 & 8,8 & 0,93 \\
\hline Medicamento para depres & & & & & \\
\hline Não usa & 52 & 78,8 & 222 & 92,5 & \\
\hline Usa & 14 & 21,2 & 18 & 7,5 & 0,00 \\
\hline Reposição do hormônio tir & & & & & \\
\hline Não faz & 64 & 97,0 & 231 & 96,2 & \\
\hline $\mathrm{Faz}$ & 2 & 3,0 & 9 & 3,8 & 0,78 \\
\hline Estilo de vida & & & & & \\
\hline $\begin{array}{l}\text { Consumo diário de frutas } \\
\text { aproximadamente } 100 \mathrm{a}\end{array}$ & & & & & \\
\hline$\geq 3$ porções & 17 & 25,8 & 4 & 1,7 & \\
\hline$<3$ porções & 49 & 74,2 & 236 & 98,3 & 0,00 \\
\hline Compulsão alimentar ${ }^{\mathrm{a}}$ & & & & & \\
\hline Não & 15 & 22,7 & 78 & 32,5 & \\
\hline Sim & 51 & 77,3 & 162 & 67,5 & 0,13 \\
\hline Hiperfagia noturna ${ }^{\mathrm{a}}$ & & & & & \\
\hline Não & 40 & 60,6 & 165 & 68,8 & \\
\hline Sim & 26 & 39,4 & 75 & 31,2 & 0,21 \\
\hline Atividade física ${ }^{\mathrm{a}}$ & & & & & \\
\hline Ativa & 37 & 56,1 & 153 & 63,8 & \\
\hline Pouco ativa & 29 & 43,9 & 87 & 36,2 & 0,25 \\
\hline Bebida alcoólica & & & & & \\
\hline Não & 35 & 53,0 & 114 & 47,5 & \\
\hline Sim & 31 & 47,0 & 126 & 52,5 & 0,43 \\
\hline Tabagismo $^{\mathrm{a}}$ & & & & & \\
\hline Não & 44 & 66,7 & 151 & 62,9 & \\
\hline Sim & 22 & 33,3 & 89 & 37,1 & 0,58 \\
\hline
\end{tabular}

Tabela 3. (continuação)

\begin{tabular}{lccccc}
\hline Sociais & & & & & \\
\hline Grau de escolaridade $^{\mathrm{a}}$ & 47 & 71,2 & 155 & 64,6 & \\
$\quad$ Médio & 19 & 28,8 & 85 & 35,4 & 0,31 \\
$\quad$ Baixo & & & & & \\
$\quad$ Nível socioeconômico & \\
$\quad$ Médio & 50 & 75,8 & 152 & 63,3 & \\
$\quad$ Baixo & 16 & 24,2 & 88 & 36,7 & 0,06 \\
Estado civila & & & & & \\
$\quad$ Solteira & 26 & 39,4 & 78 & 32,5 & \\
$\quad$ Casada ou não mais casada & 40 & 60,6 & 162 & 67,5 & 0,30 \\
\hline
\end{tabular}

a: dados disponíveis no prontuário médico; b: dados sem registro no prontuário médico obtidos no momento de confirmação dos critérios de definição dos grupos.

Tabela 4. Associação entre variáveis selecionadas e baixo risco cardiometabólico em mulheres obesas do estudo

\begin{tabular}{|c|c|c|c|c|c|c|}
\hline Variáveis & $\begin{array}{c}\mathrm{OR} \\
\text { bruto }\end{array}$ & IC 95\% & $\begin{array}{r}\text { Valor } \\
\text { de p }\end{array}$ & $\begin{array}{c}\mathbf{O R} \\
\text { ajustado }\end{array}$ & IC 95\% & $\begin{array}{l}\text { Valor } \\
\text { de } p\end{array}$ \\
\hline \multicolumn{7}{|c|}{ Doenças crônicas não transmissíveis } \\
\hline \multicolumn{7}{|l|}{ Pais diabéticos ${ }^{\mathrm{a}}$} \\
\hline Pelo menos um & 1,0 & & & 1,0 & & \\
\hline Nenhum & 1,3 & $0,8-2,3$ & 0,32 & 1,3 & $0,7-2,2$ & 0,43 \\
\hline \multicolumn{7}{|l|}{ Pais hipertensos ${ }^{\mathrm{a}}$} \\
\hline Pelo menos um & 1,0 & & & 1,0 & & \\
\hline Nenhum & 1,1 & $0,6-2,1$ & 0,70 & 1,1 & $0,6-2,1$ & 0,81 \\
\hline \multicolumn{7}{|l|}{ Pais obesos ${ }^{\mathrm{a}}$} \\
\hline Pelo menos um & 1,0 & & & 1,0 & & \\
\hline Nenhum & 0,8 & $0,5-1,4$ & 0,45 & 0,9 & $0,5-1,5$ & 0,62 \\
\hline \multicolumn{7}{|l|}{ Início da obesidadea } \\
\hline Precoce & 1,0 & & & 1,0 & & \\
\hline Tardia & 0,5 & $0,3-0,9$ & 0,02 & 0,5 & $0,3-0,9$ & 0,03 \\
\hline \multicolumn{7}{|c|}{ Fatores demográficos e socioeconômicos } \\
\hline \multicolumn{7}{|l|}{ Cor da peleb } \\
\hline Parda ou preta & 1,0 & & & 1,0 & & \\
\hline Branca & 1,0 & $0,5-1,8$ & 0,90 & 0,9 & $0,5-1,7$ & 0,68 \\
\hline \multicolumn{7}{|l|}{ Estado civil ${ }^{\mathrm{b}}$} \\
\hline $\begin{array}{l}\text { Casada ou não } \\
\text { mais casada }\end{array}$ & 1,0 & & & 1,0 & & \\
\hline Solteira & 1,3 & $0,7-2,3$ & 0,38 & 1,2 & $0,7-2,2$ & 0,52 \\
\hline \multicolumn{7}{|c|}{ Grau de escolaridade ${ }^{b}$} \\
\hline Baixo & 1,0 & & & 1,0 & & \\
\hline Médio & 1,4 & $0,7-2,5$ & 0,32 & 0,9 & $0,4-2,0$ & 0,87 \\
\hline \multicolumn{7}{|l|}{ Nível } \\
\hline Baixo & 1,0 & & & 1,0 & & \\
\hline Médio & 1,8 & $1,0-3,3$ & 0,07 & 2,0 & $0,9-4,4$ & 0,07 \\
\hline \multicolumn{7}{|c|}{ Estilo de vida e fatores psicocomportamentais } \\
\hline \multicolumn{7}{|c|}{$\begin{array}{l}\text { Consumo diário de } \\
\text { frutas (aproximada- } \\
\text { mente } 100 \mathrm{~g} / \text { porção) }\end{array}$} \\
\hline$<3$ porções & 1,0 & & & 1,0 & & \\
\hline$\geq 3$ porções & 19,6 & $5,7-67,0$ & 0,00 & 20,1 & $5,6-71,9$ & 0,00 \\
\hline \multicolumn{7}{|l|}{ Atividade física ${ }^{c}$} \\
\hline Pouco ativa & 1,0 & & & 1,0 & & \\
\hline Ativa & 0,7 & $0,4-1,3$ & 0,28 & 0,7 & $0,3-1,2$ & 0,19 \\
\hline \multicolumn{7}{|c|}{$\begin{array}{l}\text { Consumo de bebida } \\
\text { alcoólica }^{\circ}\end{array}$} \\
\hline Sim & 1,0 & & & 1,0 & & \\
\hline Não & 1,3 & $0,7-2,2$ & 0,38 & 1,4 & $0,7-2,8$ & 0,29 \\
\hline
\end{tabular}


Tabela 4. (continuação)

\begin{tabular}{|c|c|c|c|c|c|c|}
\hline \multicolumn{7}{|l|}{ Tabagismoc } \\
\hline Sim & 1,0 & & & 1,0 & & \\
\hline Não & 1,2 & $0,7-2,0$ & 0,59 & 1,2 & $0,6-2,3$ & 0,64 \\
\hline \multicolumn{7}{|c|}{ Compulsão alimentarc } \\
\hline Sim & 1,0 & & & 1,0 & & \\
\hline Não & 0,6 & $0,3-1,1$ & 0,12 & 0,6 & $0,3-1,2$ & 0,13 \\
\hline \multicolumn{7}{|c|}{ Hiperfagia noturnac ${ }^{c}$} \\
\hline Sim & 1,0 & & & 1,0 & & \\
\hline Não & 0,7 & $0,4-1,2$ & 0,23 & 0,9 & $0,5-1,8$ & 0,78 \\
\hline \multicolumn{7}{|c|}{ Marcadores inflamatórios e uso de medicamentos } \\
\hline \multicolumn{7}{|l|}{$\mathrm{PCR}^{\mathrm{d}}$} \\
\hline$>3,70 \mathrm{mg} / \mathrm{L}$ & 1,0 & & & 1,0 & & \\
\hline$\leq 3,70 \mathrm{mg} / \mathrm{L}$ & 5,0 & $2,7-9,1$ & 0,00 & 4,1 & $2,0-8,3$ & 0,00 \\
\hline \multicolumn{7}{|l|}{ AdipoQd } \\
\hline$\leq 10,00 \mu \mathrm{g} / \mathrm{mL}$ & 1,0 & & & 1,0 & & \\
\hline$>10,00 \mu \mathrm{g} / \mathrm{mL}$ & 2,8 & $1,5-5,1$ & 0,00 & 2,3 & $1,1-4,8$ & 0,03 \\
\hline \multicolumn{7}{|c|}{$\begin{array}{l}\text { Uso de medicamentos } \\
\text { para depressã } 0^{d}\end{array}$} \\
\hline Sim & 1,0 & & & 1,0 & & \\
\hline Não & 0,3 & $0,1-0,6$ & 0,00 & 0,2 & $0,1-0,7$ & 0,01 \\
\hline \multicolumn{7}{|c|}{$\begin{array}{l}\text { Reposição do } \\
\text { hormônio tireoidiano }{ }^{d}\end{array}$} \\
\hline Sim & 1,0 & & & & & \\
\hline Não & 1,2 & $0,3-5,9$ & 0,79 & 1,1 & $0,2-6,4$ & 0,94 \\
\hline \multicolumn{7}{|c|}{$\begin{array}{l}\text { Uso de contraceptivo } \\
\text { oral }^{d}\end{array}$} \\
\hline Sim & 1,0 & & & 1,0 & & \\
\hline Não & 2,3 & $1,1-4,9$ & 0,04 & 1,4 & $0,5-3,8$ & 0,47 \\
\hline \multicolumn{7}{|c|}{$\begin{array}{l}\text { Reposição hormonal a } \\
\text { partir da menopausa }^{d}\end{array}$} \\
\hline Sim & 1,0 & & & 1,0 & & \\
\hline Não & 0,8 & $0,3-2,5$ & 0,73 & 0,8 & $0,2-3,2$ & 0,80 \\
\hline
\end{tabular}

a: ajustado por variáveis do mesmo bloco; b: ajustadas pela variável início da obesidade; c: ajustadas pelas variáveis início da obesidade e nível socioeconômico; d: ajustadas pelas variáveis início da obesidade, nível socioeconômico, consumo de frutas e compulsão alimentar.

Tabela 5. Avaliação da contribuição de cada bloco de variáveis para 0 ajuste do modelo do estudo

\begin{tabular}{lccccc}
\hline & $\begin{array}{c}\text { Função } \\
\text { desvio }\end{array}$ & $\begin{array}{c}\text { Graus de } \\
\text { liberdade }\end{array}$ & $\begin{array}{c}\text { Qui- } \\
\text { quadrado }\end{array}$ & $\begin{array}{c}\text { Valor } \\
\text { de p }\end{array}$ & $\begin{array}{c}\text { Poder } \\
\text { explicativo } \\
\text { (\%) }\end{array}$ \\
\hline Modelo vazio & $-100,87$ & & & & \\
\hline Bloco $1^{\mathrm{a}}$ & $-97,69$ & 4 & 6,35 & 0,17 & 3,15 \\
Bloc0 2 & $-95,67$ & 5 & 10,39 & 0,06 & 5,15 \\
\hline Bloc0 $3^{\mathrm{c}}$ & $-76,91$ & 8 & 47,92 & 0,00 & 23,76 \\
Bloc0 4 & $-63,51$ & 10 & 74,71 & 0,00 & 37,04 \\
\hline
\end{tabular}

a: histórico de doenças crônicas não transmissíveis (DCNT); b: histórico de DCNT, fatores demográficos e socioeconômicos; c: histórico de DCNT, fatores demográficos e socioeconômicos, estilo de vida e fatores psicomportamentais; d: histórico de DCNT, fatores demográficos e socioeconômicos, estilo de vida, fatores psicomportamentais, marcadores inflamatórios e uso de medicamentos.

Os $21,6 \%$ das mulheres obesas que não apresentaram outros FRCM mostram-se similares aos achados da literatura $(7,8)$. Inicialmente, a ausência de comorbidades nos casos poderia ser atribuída a uma predominante deposição da gordura abdominal na região subcutânea e a generalizada, distribuída de forma mais homogênea, não oferecendo ainda risco para outras comorbidades (11). Essa confirmação não teria sido possível apenas com base em dados antropométricos, sem o auxílio de métodos diagnósticos mais acurados, como a tomografia computadorizada ou a ressonância magnética (12). Aproximadamente, $80 \%$ dos indivíduos portadores de excesso de gordura na região intra-abdominal ou visceral são também obesos, muitos apresentando diabetes melito tipo 2 (DM2) ou tolerância à glicose diminuída (13). Em razão da insuficiência de recursos, não foram realizados a sobrecarga de glicose nem a dosagem da insulina, impossibilitando interpretações mais elaboradas. A associação entre baixo RCM em mulheres obesas e pais com DM sugere diferenças entre estilo de vida das participantes e dos seus pais, uma vez que a literatura é incontestável quanto à influência genética no desenvolvimento do diabetes tipo 2. Apesar da carga genética, fatores socioambientais, como baixa atividade física, dieta inadequada e obesidade, contribuem enormemente para o desenvolvimento da doença (14).

$\mathrm{O}$ baixo RCM em mulheres obesas e pais com HAS indica existência pouco provável de associação. Além disso, a hipertensão de diabéticos é mais frequentemente decorrente do próprio diabetes e da obesidade do que uma hipertensão precedente ao diabetes ou, pelo menos, detectada antes do diagnóstico do diabetes. Embora ainda não seja completamente conhecido, sabe-se que o desenvolvimento da HAS depende da interação complexa entre fatores genéticos e do estilo de vida (15).

Da mesma forma que na HAS, a associação entre baixo RCM em mulheres obesas e obesidade nos pais pode relacionar-se à simultaneidade de fatores ambientais e hereditariedade. Segundo Samaras e cols. (16), os antecedentes genéticos parecem contribuir expressivamente para a determinação da adiposidade central e total, sugerindo que alguns dos genes responsáveis pela adiposidade central e suas disfunções metabólicas seriam diferentes daqueles responsáveis pela adiposidade total. Por outro lado, em estudos epidemiológicos tem-se observado que determinadas condições ambientais, atuando durante um período crítico e específico do desenvolvimento, podem acarretar alterações de determinados genes, predispondo o indivíduo à obesidade $\mathrm{e}$ suas comorbidades (17).

A associação negativa entre início tardio da obesidade e baixo RCM aparentemente não protege as mulheres do baixo RCM, contudo, quando iniciada na 
vida adulta, pode reduzir as chances para outros RCM. Entretanto, não se exclui a possibilidade da ocorrência de distúrbios metabólicos futuros nem de se prever a ocorrência de DCNT mais tardiamente. Independentemente da época de início da obesidade, associa-se a uma incidência maior de doença coronariana, DM2 e outras DCNT (18).

Variáveis tipicamente sociais, como baixa classe social, baixa escolaridade e estado civil solteira, embora associadas positivamente ao baixo RCM, não foram ES como observado na maioria dos estudos sobre DCNT (19). Entretanto, pode-se hipotetizar que as mulheres obesas solteiras sejam as mais jovens e, portanto, mais saudáveis.

O consumo de frutas < três porções/dia foi relatado pela maioria das mulheres, mas a associação entre consumo desejável de frutas e baixo RCM foi forte, sugerindo que o consumo diário de três ou mais porções de frutas pode dificultar, retardar ou impedir o aparecimento de outros RCM entre as mulheres estudadas. Esse achado mostra-se coerente com os identificados na literatura, que indicam as fibras, sobretudo as solúveis, como protetoras de RCM e outras DCNT. A recomendação de ingestão de fibra alimentar para o adulto é de $20 \mathrm{~g}$ a $30 \mathrm{~g} /$ dia, sendo $25 \%$ de fibra solúvel (4), que corresponde, no mínimo, a três porções de $100 \mathrm{~g}$ de fruta/dia (20). As fibras solúveis contribuem para a redução dos níveis de colesterol (4). Geralmente, a quantidade consumida é insuficiente para a normalização da hipercolesterolemia e o consumo de uma maior quantidade nem sempre é bem tolerado (18). No Brasil, os estudos do IBGE (21) sobre pesquisa de orçamento familiar apontam para o baixo consumo de fibras alimentares na dieta.

As associações entre compulsão alimentar e hiperfagia noturna com baixo RCM sugerem que a ausência de tais comportamentos esteja diretamente relacionada à obesidade e não a outros RCM. Estudos realizados com mulheres obesas revelam alta frequência de compulsão alimentar e consumo calórico elevado (22). Existem evidências de que pessoas com compulsão alimentar ingerem significativamente mais alimentos do que pessoas obesas sem compulsão alimentar (23). A compulsão alimentar é bastante frequente entre os indivíduos obesos, sobretudo entre aqueles que procuram atendimento ambulatorial para perda de peso (24). Ainda que isso seja verdadeiro, a compulsão alimentar é multicausal, trazendo consequências indesejáveis para o indivíduo no convívio social (25). Nos estudos que avaliam a hiperfagia noturna como um componente da "síndrome do comer noturno", sugere-se que sua presença seja desencadeada em situações de estresse e tende a diminuir quando o problema é resolvido em parte ou totalmente (26).

A associação entre atividade física e baixo RCM divergiu da literatura. Esse achado pode ser atribuído a um viés de informação. A maioria dos casos e dos controles mencionou ser ativa. É possível que os relatos de indivíduos obesos sejam insuficientes para definir a atividade física, sendo incomuns os registros que detalhem a atividade física nos prontuários médicos. Os obesos têm dificuldade para participar de qualquer atividade física planejada, estruturada e repetida, com o objetivo de desenvolver as habilidades motoras ou de reabilitação orgânico-funcional, em decorrência da baixa capacidade física associada a outros fatores comumente observados nos indivíduos obesos (27). Por outro lado, dados identificados na literatura mostram que a definição tanto dos níveis de atividade física quanto de sedentarismo pode variar, conforme os critérios adotados no questionário aplicado. Em função dessa variabilidade de critérios, a prevalência de sedentarismo no Brasil oscila entre $26,7 \%$ e $78,2 \%$ (28).

Proporções semelhantes de casos e controles que nunca consumiram bebida alcoólica podem ter favorecido os achados. Não foi possível avaliar, neste estudo, a quantidade de álcool consumida. Essa impossibilidade pode ter contribuído para a definição de falsos positivos e negativos. Entretanto, alguns dados na literatura demonstram que o álcool ingerido com moderação, $30 \mathrm{~g} /$ dia para homens e $15 \mathrm{~g} /$ dia para mulher, mostrase ser eficaz na redução da doença aterosclerótica, associando-se a uma menor incidência de DCV. Entretanto, seu mecanismo causal ainda não foi esclarecido. Mais estabelecido está o efeito danoso resultante da ingestão excessiva, com implicações negativas para a saúde e para a qualidade de vida $(15,29)$.

A maioria dos casos e dos controles informou o não uso de antidepressivo. Entretanto, os achados não indicam a associação como um fator de proteção para o baixo RCM. Evidências científicas revelam que, entre indivíduos obesos que procuram tratamento, os índices de depressão são significativamente elevados (30). É possível que, mesmo sem usar antidepressivo, as mulheres obesas possam apresentar sintomas de depressão como fadiga, baixa autoestima, entre outros, confundidos e atribuídos a sintomas de outras comorbidades (31). A depressão desenvolvida na adolescência constitui-se em um fator de risco para obesidade na fase adulta (32), 
do mesmo modo que a obesidade, quando jovem, aumenta o risco de depressão na fase adulta (33). Essa associação pode ser explicada pela concomitância de fatores de risco comuns, como aspectos genéticos e ambientais. $\mathrm{O}$ tratamento da depressão pode aumentar o peso, enquanto a diminuição do peso tende a melhorar o humor (34). Além de se associar à obesidade, observa-se também clara associação entre DM e depressão.

A associação discreta entre não usar medicamento para hipotireoidismo e baixo RCM sugere, a princípio, que a não reposição hormonal para hipotireoidismo não esteja relacionada diretamente ao RCM, embora possa ser desencadeada a partir da obesidade. O hipotireoidismo é a mais frequente das disfunções da tireoide, presente entre $1 \%$ e $10 \%$ da população adulta, sobretudo em mulheres após os 40 anos, independentemente de ter ou não obesidade (35).

Em relação ao tratamento com reposição hormonal a partir da menopausa, a associação negativa com o baixo RCM revela que também tenha ocorrido ao acaso. Outros estudos mostram que a menopausa aumenta o risco de DCV, entretanto o grau de risco do tratamento com reposição hormonal está associado ao tipo e à quantidade do hormônio usado de forma isolada ou associado a outros hormônios (36).

As associações entre níveis da PCR e da AdipoQ e baixo RCM mostram-se coerentes com os achados na literatura, sugerindo possível papel protetor desses indicadores inflamatórios, dificultando, retardando ou impedindo o aparecimento de outros RCM. Verificase, na literatura, correlação positiva da PCR e negativa da AdipoQ com o IMC. Nos indivíduos obesos, geralmente os níveis da PCR apresentam-se mais altos e os da AdipoQ, mais baixos quando comparados a indivíduos não obesos (37). Estudiosos constataram que mulheres obesas metabolicamente saudáveis apresentaram níveis mais baixos da PCR quando comparadas com mulheres com resistência à insulina e que elevações discretas nas concentrações de PCR podem prever o aparecimento de DCV (38). Valores de PCR acima de $10 \mathrm{mg} / \mathrm{dL}$ sugerem alteração transitória dos níveis de PCR, possivelmente em decorrência de uma infecção e/ou um estado inflamatório agudo (39) ou na presença de elevado consumo de gorduras, especialmente as trans e as gorduras saturadas (40). Nessas situações, a PCR é considerada por estudiosos como um indicador com menor poder para avaliar risco cardiovascular (39).

Entre o conjunto de variáveis analisadas, constatou-se que as relacionadas ao estilo de vida e aos fatores psico- comportamentais contribuíram de maneira significativa para a explicação da ocorrência do baixo RCM em mulheres obesas. Esses achados confirmam a necessidade de mudanças de comportamentos que integram a cadeia de risco na determinação da obesidade e de outras $\operatorname{DCNT}(19)$.

Em conclusão, o estudo buscou evidenciar a presença de fatores de proteção em mulheres que já apresentavam obesidade e não fatores de risco para o desenvolvimento da obesidade, conforme identificado na maioria dos estudos epidemiológicos, destacando-se como possíveis protetores a associação positiva estatisticamente significante entre baixo RCM e o consumo desejável de frutas, níveis da $\mathrm{PCR} \leq 3,70 \mathrm{mg} / \mathrm{L}$ e da adiponectina plasmática > $10,00 \mu \mathrm{g} / \mathrm{mL}$, sugerindo dificuldade, retardo ou impedimento de aquisição de outros fatores de risco ou doenças metabólicas em mulheres obesas. Por outro lado, o início da obesidade na fase adulta e o não uso de antidepressivos associaram-se negativamente com o baixo RCM ( $\mathrm{p}$ $<0,05)$, não se configurando como fatores de proteção.

Estudo financiado pelo Ministério da Saúde/Conselho Nacional de Desenvolvimento Científico e Tecnológico (MS/CNPq), Processo $n^{\circ}$. 505671/2004-2

Declaração: os autores declaram não haver conflitos de interesse científico neste estudo.

\section{REFERÊNCIAS}

1. Sociedade Brasileira de Cardiologia. I Diretriz Brasileira de Diagnóstico e Tratamento da Síndrome Metabólica. Departamento de Aterosclerose (SBC). Arq Bras Cardiol. 2005;84:1-28.

2. Ribeiro Filho FF, Mariosa LS, Ferreira SRG, Zanella MT. Gordura visceral e síndrome metabólica: mais que uma simples associação. Arq Bras Endocrinol Metab. 2006;50(2):230-8.

3. Volp ACP, Alfenas RCG, Costa NMB, Minim VPR, Stringueta PC, Bressan J. Capacidade dos biomarcadores inflamatórios em predizer a síndrome metabólica. Arq Bras Endocrinol Metab. 2008;52(3):537-49.

4. Sociedade Brasileira de Cardiologia. IV Diretriz Brasileira sobre Dislipidemias e Prevenção da Aterosclerose. Departamento de Aterosclerose (SBC). Arq Bras Cardiol. 2007;88:1-19.

5. Matsuzawa Y, Funahashi T, Kihara S, Shimomura I. Adiponectin and metabolic syndrome. Arterioscler Thromb Vasc Biol. 2004;24:29.

6. Szmitko PE, Teoh H, Stewart DJ, Verma S. Adiponectin and cardiovascular disease: state of the art? Am J Physiol Heart Circ Physiol. 2007;292:H1655-H1663.

7. Sims EAH. Are there who are obese, but metabolically healthy? Metabolism. 2001;50:1499-504.

8. Karelis AD, St-Pierre DH, Conus F, Rabasa-Lhoret R, Poehlman ET. Metabolic and body composition factors in subgroups of obesity: what do we know? J Clin Endocrinol Metab. 2004;89(6):2569-75.

9. Tavares J. Resiliência e educação. São Paulo: Cortez Editora; 2001.

10. Sampaio HAC, Silva BYC, Sabry MOD, Almeida PC. Índice glicêmico e carga glicêmica de dietas consumidas por indivíduos obesos. Rev Nutr. 2007;20(6):615-24. 
11. Hermsdorff HHM, Monteiro JBR. Gordura visceral, subcutânea ou intramuscular: onde está o problema? Arq Bras Endocrinol Metab. 2004;48(6):803-11.

12. Silva JLT, Guedes DP, Barbosa DS, Oliveira JA, Guedes JERP. Obesidade centrípeta e disfunções metabólicas: patogenia, mensuração e papel profilático do exercício físico. Semina: Ciências Biológicas e da Saúde, Londrina. 2002;23:49-66.

13. Kissebah $\mathrm{AH}$. Central obesity: measurement and metabolic effects. Diabetes Rev. 1997;5(1):8-20.

14. BRASIL. Ministério da Saúde. Secretaria de Atenção à Saúde. Departamento de Atenção Básica. Obesidade/Ministério da Saúde. Secretaria de Atenção à Saúde. Departamento de Atenção Básica - Brasília: Ministério da Saúde; 2006.

15. Sociedade Brasileira de Cardiologia. V Diretrizes Brasileiras de Hipertensão Arterial. Arq Bras Cardiol. 2006:1-48.

16. Samaras K, Spector TD, Nguyen TV, Baan K, Campbell LV, Kelly PJ. Independent genetic factors determine the amount and distribution of fat in women after the menopause. J Clin Endocrinol Metab. 1997;82(3)781-5.

17. Waterland RA, Garza C. Potential for metabolic imprinting by nutritional perturbation of epigenetic gene regulation. Public Health Issues Infant Child Nutr. 2002;48:317-33.

18. World Health Organization. Diet, nutrition and prevention of chronic diseases. Study Group. Geneva: World Health Organization; 2003.

19. Lessa I, Araújo MJ, Magalhães L, Almeida Filho N, Aquino E, Costa MC. Simultaneidade de fatores de risco cardiovascular modificáveis na população adulta de Salvador (BA), Brasil. Rev Panam Salud Publica. 2004;16(2):131-7.

20. Franco G. Tabela de composição química dos alimentos. 9.ed. Rio de Janeiro: Atheneu; 1999.

21. Instituto Brasileiro de Geografia e Estatística (IBGE). Pesquisa de Orçamentos Familiares 2002-2003: análise da disponibilidade domiciliar de alimentos e do estado nutricional no Brasil. Rio de Janeiro; 2004.

22. Borges MBF. Estudo do transtorno da compulsão alimentar periódica em população de obesos e sua associação com depressão e alexitimia [Dissertação]. São Paulo: Universidade Federal de São Paulo; 1998.

23. Goldfein JA, Walsh BT, Devlin MJ, Janet L. Lachaussée H, Kissileff R. Eating behavior in binge eating disorder. Int J Eat Disord. 2006;14(4):427-31.

24. Borges MBF, Jorge MR. Evolução histórica do conceito de compulsão alimentar. Psiq Prat Med. 2000;33(4):113-18.

25. Callaway CW, Greenwood MRC. Introduction to the workshop on methods for characterizing human obesity. Int $\mathrm{J}$ Obes. 1984;8:477-80.
26. Stunkard A. Two eating disorders: binge eating disorder and the night eating syndrome. Appetite. 2000;34:333-4.

27. Nahas MV. Atividade física, saúde e qualidade de vida. Londrina: Midiograf; 2001.

28. Malta DC, Moura EC, Castro AM, Morais Neto OL, Monteiro CA. Padrão de atividade física em adultos brasileiros: resultados de um inquérito por entrevistas telefônicas, 2006. Epidemiol Serv Saúde. 2009;18(1):7-16.

29. Novazzi JP, Relvas WGM. Fumo e álcool: papel na doença cardiovascular. Socesp. 2000:10(6).

30. Dobrow IJ, Kamenetz C, Devlin MJ. Aspectos psiquiátricos da obesidade. Rev Bras Psiquiatr. 2002;24(suppl.3):63-7.

31. Teng TC, Humes EC, Demetrio FN. Depressão e comorbidades clínicas. Rev Psiq Clín. 2005;32(3):149-59.

32. Pine DS, Goldstein RB, Wolk S, Weissman MM. The association between childhood depression and adulthood body mass index. Pediatrics. 2001;107:1049-56.

33. Stunkard AJ, Faith MS, Allisn KC. Obesity and depression. Biol Psychiatry. 2003;54:330-7.

34. Dymek MP, Le Grange D, Neven K, Alverdy J. Quality of life and psychosocial adjustment in patients after Roux-en-Y gastric bypass: a brief report. Obes Surg. 2001;11:32-9.

35. Krotkiewski M.Thyroid hormones in the pathogenesis and treatment of obesity. Eur J Pharmacol. 2002;440:85-98.

36. I Diretriz Brasileira sobre Prevenção de Doenças Cardiovasculares em Mulheres Climatéricas e a Influência daTerapia de Reposição Hormonal (TRH) da Sociedade Brasileira de Cardiologia (SBC) e da Associação Brasileira do Climatério (Sobrac). Arq Bras Cardiol. 2008;91(1 supl.1):1-23.

37. Yamamoto $\mathrm{Y}$, Hirose H, Saito I, Tomita M, Taniyama M, Matsubara K, et al. Correlation of the adipocyte-derived protein adiponectin with insulin resistance index and serum high-density lipoprotein-cholesterol, independent of body mass index, in the Japanese population. Clinical Science. 2002;103:137-42.

38. Park KG, Park KS, Kim MJ, Kim HS, Suh YS, Ahn JD, et al. Relationship between serum adiponectin and leptin concentrations and body fat distribution. Diabetes Res Clin Pract. 2004;63:135-42.

39. Pearson TA, Mensah GA, AlexanderWR, Anderson JL, Cannon $\mathrm{RO}$, Criqui $\mathrm{M}$, et al. Markers of inflammation and cardiovascular disease: application to clinical and public health practice: a statement for healthcare professionals from the Centers for Disease Control and Prevention and the American Heart Association. Circulation. 2003;107(3):499-511.

40. Shen J, Ordovas JM. Impact of genetic and environmental factors on hsCRP concentrations and response to therapeutic agents. Clin Chem. 2009;55:256-64. 